\title{
Intergenerational mobility: measurement and the role of borrowing constraints and inherited tastes
}

\author{
Jordi Caballé ${ }^{1}$ (D)
}

Received: 8 August 2016/ Accepted: 2 September 2016 / Published online: 17 September 2016 (C) The Author(s) 2016. This article is published with open access at Springerlink.com

\begin{abstract}
In this paper, I present some popular measures of mobility in economic outcomes within a family across generations. I also discuss two of the most important factors preventing intergenerational mobility: existence of financially constrained individuals and transmission of tastes from parents to children. Finally, I show how these two factors could give raise to dramatic reversals of fortune affecting successive generations of the same dynasty. I will cast the results of the different models I use in terms of the previous measures of intergenerational mobility.
\end{abstract}

Keywords Intergenerational mobility $\cdot$ Inherited tastes $\cdot$ Borrowing constraints

JEL Classification J62 $\cdot$ E21 $\cdot$ I26

\section{Introduction}

The analysis of intergenerational mobility refers to the study of the lack of persistence in outcomes across generations within the same family. From an Economics viewpoint, the outcomes that are subject of study range from quantitative variables

This paper is based on the Presidential Address delivered by the author in the XXXVIII Symposium of the Spanish Economic Association (Santander) on December 12, 2013. The paper has benefited from valuable comments from an anonymous referee. Financial support from the Government of Spain/FEDER through grant ECO2015-67602-P, the Severo Ochoa Program through grant SEV-2015-0563; and the Generalitat of Catalonia through grant 2014-SGR-803 is gratefully acknowledged.

$凶$ Jordi Caballé

jordi.caballe@uab.es

1 Departament d'Economia i d'Història Econòmica, MOVE and Barcelona GSE,

Universitat Autònoma de Barcelona, Edifici B, Bellaterra, 08193 Barcelona, Spain 
like consumption, wealth, income or earnings, to qualitative variables like occupation or education attainment. The degree of intergenerational mobility in these economic variables tells us how easily families move between different parts of the associated distribution and, thus, it has been typically used to measure equality of opportunity within an economy.

Intergenerational mobility is a topic that has drawn the attention to economists since its presence tends to be associated with an inefficient allocation of resources. For instance, consider an environment where the optimal investment in education for each individual were a function of his learning ability (or innate talent) and that the learning ability of individuals were independent of their predecessors' ability. In this case, the optimal allocation of education expenditures should be incompatible with any type of correlation in educational attainment between parents and children. The intergenerational persistence in human capital, possibly arising from the correlation between parental wealth and education investment or from other environmental factors acting during the early periods of children's life, would call for public intervention to restore ex-ante optimality.

One of the first issues that the research on intergenerational mobility deals with refers to its measurement. In Sect. 2, I will discuss some of the traditional techniques of measurement. These techniques are based on single numerical values, like the intergenerational correlation and the intergenerational elasticity, or provide more exhaustive information, like the transition matrices. Finally, I will present a more recent measure aimed at capturing upward mobility.

While some of the factors underlying the phenomenon of intergenerational persistence of economic variables across the different generations of the same dynasty are purely biological (like genetic inheritance) or cultural (like transmission of tastes, aspirations, or neighborhood effects), others have a more economic component, like the existence of borrowing constraints, which condemn poor families to remain poor across generations since they cannot afford the investment in one of the more efficient social elevators, namely, education. Section 3 reviews briefly these potential drivers of socioeconomic immobility.

Sections 4 and 5 pay attention to two of the most popular mechanisms undermining intergenerational mobility. The first mechanism is not necessarily connected to any kind of inefficiency as it has to do with the way preferences of individuals are shaped in the early periods of their lives. If children end up having the same preferences as their parents, then they will tend to take the same economic decisions concerning the consumption profile along their life cycle, occupation or attitude towards work effort. Therefore, intergenerational persistence in consumption and earnings should be observed as a result of this process of preference formation. The second mechanism has however clear welfare implications since it is linked to the existence of financially constrained individuals who cannot implement their optimal decisions like, for instance, those concerning the optimal investment in either their own or their children's education. For this second mechanism, I will also discuss the positive implications of some popular policy measures aimed at remedying the immobility brought about by financial constraints.

Section 6 analyzes the possibility of dramatic reversals of fortune within a family and reviews some of the driving factors for this extreme form of intergenerational 
mobility. Those factors are typically associated with the conjecture formulated by the famous steel businessman Andrew Carnegie, according to which the sons that receive a large inheritance from their parents tend to allocate less effort to work. Section 7 concludes the paper.

\section{The measurement of intergenerational mobility}

Let me first mention that the empirical analysis of intergenerational income mobility has focussed on fathers and sons since the rate of female labor force participation in most countries has been quite low in the past so that there is not enough data to draw conclusions about the comparison between mothers and daughters. It is also important to point out that the study of intergenerational mobility in quantitative variables should rely on the permanent values of these variables in order to minimize potential biases and measurement errors arising from using one year observations for both fathers and sons. Those permanent values are obtained by averaging the observed values over several years. Moreover, it is necessary to control for the ages of both fathers and sons at the time those variables are measured.

One of the most comprehensive instruments to measure intergenerational mobility for an economic variable relies on the analysis of the corresponding transition matrix $\mathbb{P}$. To construct this matrix, the values of the variable under study are divided in class intervals or bins so that each value $p_{i j}$ of the cell $(i, j)$ of the matrix $\mathbb{P}$ gives us the relative conditional frequency that the value of the relevant variable for the son lies in the bin $j$ given that the value of the same variable for his father lies in the bin $i$. Thus, a transition probability matrix with the values of all its cells concentrated around the diagonal will be a signal of persistence (or immobility).

Let us assume first that the variable under study is quantitative, like earnings, income, wealth, or consumption. ${ }^{1}$ We can divide the population of fathers and sons into $Q$ quantiles for the quantitative variable we are considering so that the value $p_{i j}$ is just the relative conditional frequency that the variable for the son will take a value lying in the quantile $j$ given that the corresponding value for the father lies in the quantile $i$. Just for illustrative purposes, let us consider the following three transition matrices providing information about the degree of mobility among quintiles of earnings in the US (Isaacs 2007), Spain (Cervini-Plá 2011) and Sweden (Jäntti et al. 2006):

\begin{tabular}{llllll}
\hline Father & \multicolumn{5}{c}{ Son } \\
\cline { 2 - 5 } & Top & Fourth & Middle & Second & Bottom \\
\hline Top quintile & .39 & .23 & .14 & .15 & .09 \\
Fourth quintile & .26 & .32 & .19 & .15 & .08 \\
Middle quintile & .19 & .17 & .23 & .24 & .17 \\
Second quintile & .10 & .18 & .24 & .23 & .25 \\
Bottom quintile & .06 & .11 & .18 & .23 & .42 \\
\hline
\end{tabular}

Transition matrix of earnings: US (Source: Isaacs 2007. Data: PSID 2006)

\footnotetext{
1 Earnings are the compensations to all types of labor services including entrepreneurial labor, income refers to earnings plus capital income and government transfers, and wealth is the value of all financial and real assets minus the value of all debts
} 


\begin{tabular}{|c|c|c|c|c|c|}
\hline \multirow[t]{2}{*}{ Father } & \multicolumn{5}{|c|}{ Son } \\
\hline & Top & Fourth & Middle & Second & Bottom \\
\hline Top quintile & .33 & .22 & .16 & .16 & .13 \\
\hline Fourth quintile & .21 & .23 & .22 & .18 & .16 \\
\hline Middle quintile & .21 & .23 & .20 & .19 & .17 \\
\hline Second quintile & .15 & .16 & .23 & .22 & .24 \\
\hline Bottom quintile & .10 & .16 & .19 & .25 & .30 \\
\hline
\end{tabular}

Transition matrix of earnings: Spain (Source: Cervini-Plá 2011. Data: Encuesta de Condiciones de Vida 2005)

\begin{tabular}{llllll}
\hline Father & \multicolumn{5}{c}{ Son } \\
\cline { 2 - 6 } & Top & Fourth & Middle & Second & Bottom \\
\hline Top quintile & .37 & .19 & .14 & .14 & .16 \\
Fourth quintile & .23 & .22 & .20 & .18 & .17 \\
Middle quintile & .17 & .22 & .22 & .21 & .18 \\
Second quintile & .13 & .20 & .24 & .22 & .21 \\
Bottom quintile & .11 & .18 & .21 & .24 & .26 \\
\hline
\end{tabular}

Transition matrix of earnings: Sweden (Source: Jäntti et al. 2006. Data: Statistics Sweden's administrative registers, cohort born in 1962)

If we compare the previous transition matrices for the US and Sweden we see that, while the probability that the high earnings (in the top quintile) families remain in the same quintile are similar in both countries (39 versus $37 \%$ ), the probability of escaping from poverty in Sweden is much higher than in the US as the probability of remaining in the lower quintile in the US is $42 \%$ while in Sweden it is just $26 \%$. Note also that extreme movements across quintiles in Sweden are much more likely than in the US. For instance, in Sweden the probability of moving intergenerationally from the top quintile to the bottom quantile (extreme downward mobility) is $16 \%$ and the probability of moving from the bottom quantile to the top quintile (extreme upward mobility) is $11 \%$. This probability is almost half in the US (9 and $6 \%$, respectively). The transition matrix corresponding to Spain exhibits larger extreme mobility than in the US but lower than in Sweden. Moreover, Spain exhibits less persistence of earnings in the top quintile than both the US and Sweden and intermediate persistence in the bottom quintile. We see thus that from the transition matrices we can infer information both about the degree of persistence in each quintile and the degree of mobility across different quintiles.

If we would like to know which of the three previous countries exhibits more mobility, we should summarize all the information contained in the transition matrices in a single number that could be easily compared across countries. Of course, the mapping from the set of transition matrices into the set of real numbers involves a severe loss of information since the resulting single number cannot tell us neither whether the type of mobility is strong (across distant quantiles) or weak (across near quantiles) nor whether the degree of persistence within each quantile is high or low. 
Since a transition matrix is a stochastic matrix, i.e., the values of the cells in each row must add up to one, it has an eigenvalue equal to one while its other eigenvalues are smaller or equal to one. In order to measure the degree of mobility implicit in a given transition matrix we need to find a measure of the "distance" of this matrix with respect to the identity matrix, which represents absolute immobility across quantiles. One popular measure of intergenerational mobility is given by one minus the second largest eigenvalue of the transition matrix. Note in this respect that the identity matrix has all its eigenvalues equal to one and, therefore, its measure of intergenerational mobility is equal to zero. Moreover, a $Q \times Q$ matrix whose cell values are all equal to $1 / Q$, which is an environment sometimes described as "complete mobility", has an eigenvalue equal to one and all the other eigenvalues equal to zero so that its measure of intergenerational mobility is equal to 1 . The values for this measure of intergenerational mobility associated with the above transition matrices for the earnings in the US, Spain and Sweden are 0.606, 0.773, and 0.780, respectively, which confirms the highest degree of intergenerational earnings mobility in Sweden and the intermediate position of Spain among these three countries. It is worth mentioning that these numbers challenge the idea of "American exceptionalism", a term that referred to the supposed exceptionally high rates of social mobility in the US.

In the same spirit of the previous real valued measure, the literature on intergenerational mobility has proposed the average quantile move,

$$
A Q M=\frac{\sum_{i=1}^{Q} \sum_{j=1}^{Q}|i-j| p_{i j}}{Q}
$$

which is the sum of the transition probabilities weighted by the jump in the number of quantiles between fathers and sons. The identity matrix has an $A Q M$ equal to zero as in this case $p_{i i}=1$ and $p_{i j}=0$ for $i, j=1, \ldots, Q$ and $i \neq j$. Note that the $A Q M$ discriminates between strong (across distant quantiles) or weak (across near quantiles) mobility.

Similarly, the normalized trace index (Shorrocks 1978),

$$
N T I=\frac{Q-\operatorname{trace}(\mathbb{P})}{Q-1},
$$

is another measure of the distance from the identity matrix. The NTI is equal to zero for the identity matrix and is equal to one for a matrix displaying "complete mobility".

Transition matrices can also be constructed for qualitative variables or attributes, like occupation type, working sector, or education level. In this case, the different bins are constructed just taking into account the different qualitative values of the variable and not the frequency of individuals lying in each bin. Therefore, in this case we cannot guarantee that the different classes have exactly the same size for each generation. Let us illustrate this type of transition matrices with the following matrix providing information about the degree of intergenerational mobility in education attainment in Spain (Cervini-Plá 2011): 


\begin{tabular}{lllllll}
\hline Father & \multicolumn{7}{c}{ Son } & & \\
\cline { 2 - 7 } & 5 & 4 & 3 & 2 & 1 & 0 \\
\hline 5 & .78 & .01 & .16 & .04 & .01 & .00 \\
4 & .44 & .12 & .36 & .08 & .00 & .00 \\
3 & .57 & .01 & .31 & .07 & .03 & .00 \\
2 & .41 & .02 & .34 & .18 & .05 & .00 \\
1 & .35 & .02 & .25 & .24 & .14 & .00 \\
0 & .11 & .02 & .18 & .35 & .34 & .00 \\
\hline
\end{tabular}

0: Did not finish primary education, 1: Primary education, 2 : Secondary education (first step),

3: Secondary education (second step), 4: Vocational qualification, 5: Higher education (university).

Transition matrix of education attainment: Spain (Source: Cervini-Plá 2011. Data: Encuesta de Condiciones de Vida 2005)

We can infer from the previous transition matrix the large degree of persistence of the high levels of education in Spain since the conditional probability that a son has a college degree given that his father also has it is $78 \%$. Similarly, the following matrix provides information about intergenerational mobility across types of occupation in the US (Long and Ferrie 2013):

\begin{tabular}{llllll}
\hline Father & \multicolumn{5}{c}{ Son } \\
\cline { 2 - 6 } & H W C & L W C & F & S/Semi. & Unsk. \\
\hline High White Collar & .62 & .12 & .00 & .21 & .05 \\
Low White Collar & .50 & .16 & .00 & .26 & .08 \\
Farmer & .24 & .08 & .13 & .43 & .12 \\
Skilled/Semiskilled & .33 & .11 & .01 & .46 & .09 \\
Unskilled & .25 & .10 & .01 & .51 & .13 \\
\hline
\end{tabular}

"High White Collar": professional, technical, and kindred; managers, officials, and proprietors.

"Low White Collar": clerical and sales. "Farmer": farm owners and farm managers.

"Skilled/Semiskilled": craftsmen and operatives. "Unskilled": service workers and laborers, including farm laborers.

Transition probabilities of occupations US. (Source: Long and Ferrie 2013)

Note that the previous two matrices do not contain information about the fraction of individuals (either fathers or sons) in a given bin. However, if the previous matrices where time independent, we could easily compute its associated ergodic stochastic probability vector, which is the vector of frequencies in the long run of the different bins, which turns out to be independent of the initial distribution of frequencies. For instance, from the previous transition matrix of occupations in the US we can compute the following distribution of the five types of occupation in the long run:

\begin{tabular}{lllll}
\hline H W C & L W C & F & S/Semi. & Unsk. \\
\hline .49 & .12 & .00 & .32 & .07 \\
\hline
\end{tabular}

We see thus that in the long run the class of farmers will have a negligible weight in the total working population of the US, while almost half of the population will be composed of highly skilled workers. 
I should also mention that, since the frequencies of individuals in the different bins are not equal in the matrices for qualitative variables, if there are bins that are associated with unfavorable outcomes like, for instance, the bin composed of unskilled or poor individuals, policy makers should implement policies aimed at reducing the fraction of individuals belonging to this bin in the long run. Those policies could take the form of universal provision of public education so as to remove the borrowing constraints that prevent the investment in skill acquisition, tax reforms, or other programs of financial aid.

There are other real-valued measures of intergenerational mobility that do not need the previous construction of transition matrices. The most popular of them is based on the intergenerational correlation $(I C)$, which is simply the coefficient of correlation between the variable $x_{c}$ under study for the sons and the same variable $x_{p}$ for the corresponding father. Thus, since this value of the correlation coefficient is a measure of intergenerational persistence or immobility, then $1-I C$ is a natural measure of intergenerational mobility.

The $I C$ is closely related with another popular real-valued measure of persistence, namely, the intergenerational elasticity $(I E)$. The $I E$ is just the estimate of the coefficient $\beta$ in the following regression:

$$
\widehat{x}_{c}=\beta \widehat{x}_{p}+\varepsilon
$$

where $\widehat{x}_{c}$ refers to the log-deviation from its mean of the variable under study for the sons and $\widehat{x}_{p}$ refers to the log-deviation from its mean of the variable for the corresponding father, and $\varepsilon$ is the typical perturbation term. Note that the $I E$ gives the expected elasticity of the variable $x_{c}$ with respect to $x_{p}$. Obviously, the higher is the value of $\beta$, the higher will be the dependence of a son's status from his father's status. Thus, $1-I E$ is a natural measure of intergenerational mobility. Moreover, if the distributions of the variables $\widehat{x}_{c}$ and $\widehat{x}_{p}$ have the same variance then the $I E$ coincides with the coefficient of correlation between $\widehat{x}_{c}$ and $\widehat{x}_{p}$. However, if these two variables have different variances, then the relationship between the intergenerational correlation $I C$ and the intergenerational elasticity $I E$ satisfies

$$
I E=\left(\frac{\sigma_{\widehat{c}}}{\sigma_{\widehat{p}}}\right) \cdot I C,
$$

where $\sigma_{\widehat{c}}$ and $\sigma_{\widehat{c}}$ are the standard deviations of the variables $\widehat{x}_{c}$ and $\widehat{x}_{p}$, respectively. Note that these two measures of intergenerational mobility can only be used for quantitative variables.

Several studies, like those of Mazumder (2005), Nicoletti and Ermisch (2007), Blanden et al. (2004), Cervini-Plá (2015) have estimated the $I E$ of earnings for several countries and their results give values of the $I E$ between 0.5 and 0.6 for the US, 0.3 for UK, 0.43 for Spain and 0.25 for Nordic countries. This agrees with the information provided with the previous transition probability matrices of earnings, according to which the degree of mobility of earning in the US is smaller (i.e., the $I E$ is larger) than in Europe. However, as I have already pointed out, the transition matrices provide a more detailed information, which for example allow us to attribute the lower $I E$ of 
Sweden relative to the US mainly to its higher probability of escaping from the lower quintile of earnings.

Hertz et al. (2008) provided estimates of the $I C$ of education attainment measured by the years of schooling of each individual. The South American countries with an $I C$ of around 0.6 are the ones that exhibit more persistence, which is usually attributed to the existence of pervasive borrowing constraints to finance children's education. The countries of Western Europe exhibit an average $I C$ of years of schooling of 0.4, which is even lower for Nordic countries. Those lower values tend to be associated with the strength of the welfare state. Finally, let us mention that the years of schooling in the US display an intergenerational correlation of 0.46 .

The interested reader can consult the survey of Jäntti and Jenkins (2015), which presents the previous and other measures of intergenerational mobility. Moreover, the survey of Black and Devereux (2011) contains a detailed discussion of the estimation issues concerning the $I E$.

Note that the $I E$, the $I C$, and the transition matrices for quantitative variables grouped in quantiles treat downward and upward intergenerational mobility symmetrically. However, policy makers should mainly care about providing the incentives to promote upward mobility among the poor families. Chetty et al. (2014), using the rank-rank specification of Dahl and DeLeire (2008), propose an appealing measure of upward intergenerational income mobility. They rank children based on their incomes relative to other children in the same cohort. Similarly, they rank parents of these children based on their incomes relative to other parents. Then, they characterize mobility using the slope of the rank-rank regression between parents and children, which gives the correlation between children's and parents' positions in the overall distribution of income. Obviously, the value of the slope of this regression will be negatively associated with the degree of mobility in the economy. A zero value for the slope of the rank-rank regression means that there is complete intergenerational mobility since the expected rank of the sons does not depend on the rank of their parents. Conversely, a unitary slope is a signal of complete immobility since the expected rank of the son coincides with the rank of his parent. These authors find an almost perfect linear relationship between parent ranks and child ranks in the US and that a 10 percentile point increase in parent rank corresponds on average to a 3.41 percentile point increase in the income rank of a child.

Chetty et al. replicate their analysis for different commuting zones in the US. They calculate for each zone the conditional expectation of the rank of children given that their parents are at the $25 \%$ percentile in the national income distribution of parents so that they are relatively poor parents. This conditional expectation $\bar{r}_{25}$ is clearly a measure of upward mobility. Figure 1 shows the rank-rank relationship for the commuting zones of San Francisco and Chicago and we can infer immediately from them that San Francisco exhibits higher mobility since the slope of its regression line is smaller than for Chicago. Moreover, upward mobility is also higher in San Francisco since the expected rank of a son of a parent that was at the $25 \%$ percentile is $44.4 \%$ while in Chicago it is $39.4 \%$. These authors find that upward mobility, measured by the conditional expected rank $\bar{r}_{25}$, ranges from $46.2 \%$ in Salt Lake City to $35.8 \%$ in Charlotte within the 50 largest commuting zones in the US. 


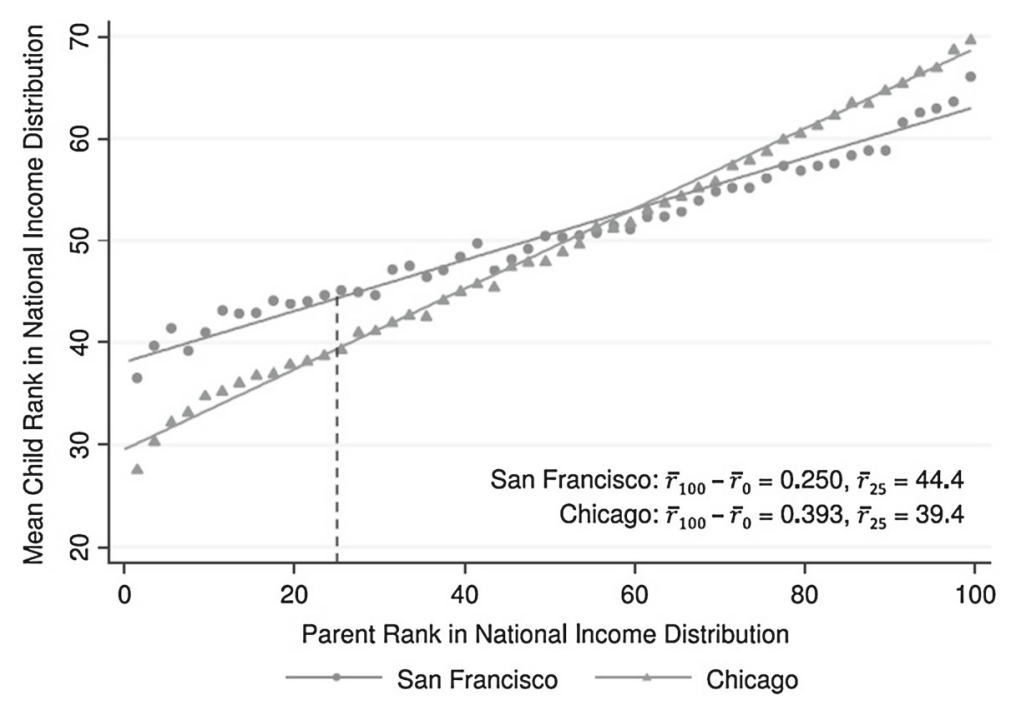

Fig. 1 Rank-rank regression in San Francisco and Chicago. (Source: Chetty et al. 2014)

\section{Intergenerational mobility and other economic characteristics}

Once we have the instruments to measure intergenerational mobility, the natural issue that arises is searching for the relevant factors driving intergenerational persistence of economic outcomes or, at least, finding other economic features that tend to be empirically associated with intergenerational persistence. Among the factors explaining persistence in earnings we can consider genetic factors, which amounts to assume that some individual characteristics (like IQ or a specific innate ability) are automatically transmitted from parents to children. Moreover, genetic transmission is strengthened under assortative mating, that is, when people choose to mate with persons similar to themselves. The importance of genetics has been empirically explored by Mazumder (2008) to find correlations in log earnings for brothers of 0.4 in the US, while Raaum et al. (2006) found a correlation of 0.2 for Norway. We see again that the presence of a strong welfare state tends to reduce the importance of genetic factors. Needless to say, the previous sibling correlations can arise not only because of genetic reasons but because of other common background variables like the neighborhood. In this respect, Page and Solon (2003) find earnings correlations among neighbors of 0.16. In order to disentangle sibling and neighbor correlations, Sacerdote (2007) restricts the analysis to adoptees, which are assumed to be randomly assigned to families without inheriting any genetic characteristic. Finally, in order to delve further into the importance of pure genetics, some authors like Behrman and Rosenzweig (2004) and Bingley et al. (2009) focused their attention to the analysis of earning correlations between twins.

Becker and Tomes $(1979,1986)$ have developed very relevant theoretical models of intergenerational earnings mobility where genetic transmission of abilities plays a key role. They assumed that children's earnings are correlated with their parents' both via the genetic inheritability of abilities and via spending on education by altruistic 


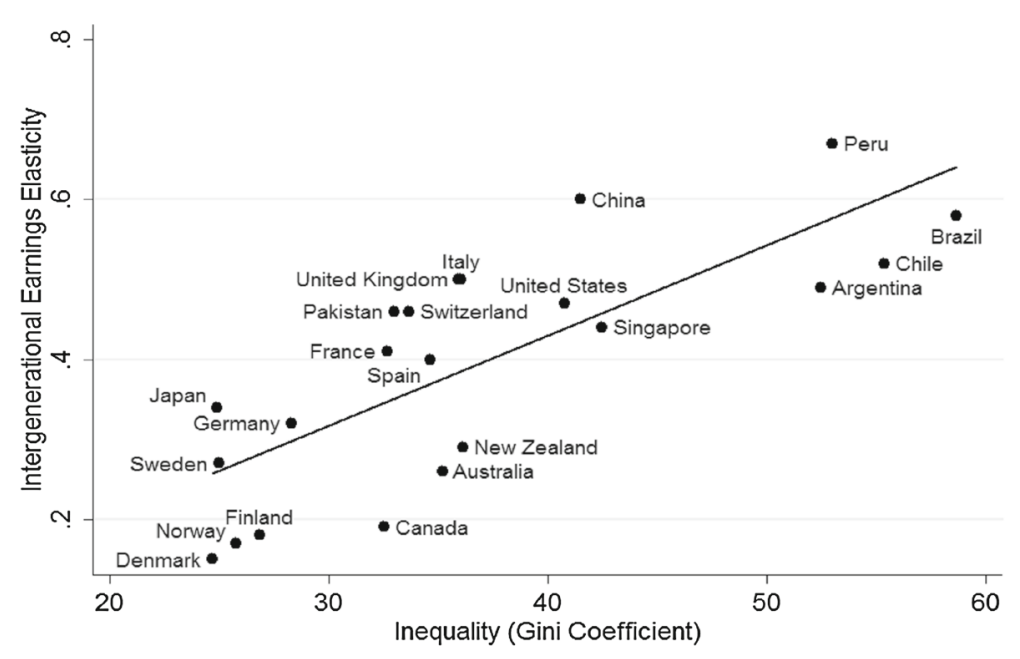

Fig. 2 The "Great Gatsby" curve. (Source: Corak 2013. Data: World Bank)

parents. Thus, children's innate abilities are correlated, but not perfectly, with those of their parents and the total labor compensation to each worker will be an increasing function of his human capital, which is in turn an increasing function of ability and investment in education. One implication of the fact that abilities are enhanced by parents' investments in their children's education is that both inherited abilities and earnings regress toward the mean but, because of the effect of parental investment in children, earnings are more intergenerationally persistent than genetically inherited abilities.

The aforementioned paper of Chetty et al. (2014) explores the correlation between upward mobility and observable characteristics of the different commuting zones in the US. They find that racial shares are empirically related to upward mobility since it is lower (even for white individuals) in zones with a larger fraction of African Americans. Other factors negatively related with upward mobility are residential race segregation, indicators of bad quality of the school system, and weak family structures measured by the fraction of single parents in the area. Finally, they report a negative relation between upward mobility and inequality measured by the Gini coefficient. Let us mention incidentally in this respect that the positive (negative) relation between intergenerational earnings persistence (mobility) and inequality also holds across countries (see Corak 2013). Figure 2 shows the relationship between the $I E$ and the Gini coefficient of different countries, which is known as the "Great Gatsby" curve.

Concerning the standard economic factors explaining persistence in earnings, the economic literature has considered several. One of the most important refers to the presence of financial constraints as they constitute a barrier to the acquisition of human capital either when the investment in education is made by parents or by the same potential students (see Solon 2004, among many others). Therefore, poor parents who are financially constrained cannot borrow to finance the education of their children and this results in a strong persistence of the socioeconomic status within the family across 
generations. The existence of a powerful welfare state that facilitates the acquisition of human capital by means, for instance, of public provision of education results in larger intergenerational earnings mobility (Ichino et al. 2011). The presence of these credit constraints has clear normative implications. If these constraints are absent, parents can borrow from their offspring's future earnings and each family will optimally invest in the human capital of their children. If both innate ability and education raise the amount of workers' human capital (or skill), then it will be optimal to invest more in high ability children under some natural assumptions (Grawe and Mulligan 2002). ${ }^{2}$ This optimal allocation of the investment in education will be distorted by the presence of financially constrained individuals and this will result in turn in a loss of aggregate output and a lower growth rate for the economy.

Borrowing constraints could also result in "poverty traps" as the members of poor families could end up remaining poor across generations. Since earnings are increasing in the amount of human capital of workers, poor individuals would never be able to obtain enough income to invest in education and, in this way, to raise their future income (Durlauf 1996; Galor and Moav 2004, 2006; Galor and Zeira 1993; Zilcha 2003). The situation depicted in this literature is summarized in the following transition matrix involving rich and poor individuals, where each of these types can be either skilled or unskilled.

\begin{tabular}{lllll}
\hline Father & \multicolumn{3}{c}{ Son } \\
\cline { 2 - 5 } & R-S & P-S & R-U & P-U \\
\hline Rich-Skilled & $a$ & $b$ & $1-a-b$ & 0 \\
Poor-Skilled & $c$ & $d$ & $1-c-d$ & 0 \\
Rich-Unskilled & $e$ & $f$ & $1-e-f$ & 0 \\
Poor-Unskilled & 0 & 0 & 0 & 1 \\
\hline
\end{tabular}

Transition matrix exhibiting poverty traps for the poor unskilled

We see from the previous matrix that being a poor unskilled individual is an absorbing state. As I have already argued, the role of public policy is thus to create conditions to allow poor unskilled individuals to escape from that poverty trap through subsidies to education, public provision of education, or any other policy that decreases the long-run relative frequency of the social class of these individuals.

Owen and Weil (1998) constructed a very elegant model relating growth, income inequality, and mobility where individuals face borrowing constraints to invest in their children's education. Moreover, they assume that ability is randomly distributed in the population independently of parents' ability so that there is no transmission of abilities through genes. Finally, skilled and unskilled labor are assumed to be complements in the production function. In this economy, as income grows all individuals face a less

\footnotetext{
2 Assume that the stock of individual human capital $h$ is an increasing function of the amounts of both innate ability $a$ and education investment $e, h(a, e)$. Then, a larger investment in high ability children is optimal if the function $h$ is concave in education investment $e$ and the cross derivative $\partial^{2} h / \partial a \partial e$ is positive. Note that the last assumption simply means that ability increases the marginal productivity of education in the technology of human capital formation.
} 
binding borrowing constraint, which in turn results in a better allocation of resources and, thus, in higher income per capita.

Another interesting feature of the economy considered by Owen and Weil is that it might exhibit multiplicity of equilibria. Due to the assumed complementarity of educated and uneducated workers, an economy with high levels of human capital will have high relative wages for uneducated workers so that it would be more likely that the children of uneducated workers will be able to afford the education cost. Downward mobility is also more likely in this developed economy since the smaller wage gap decreases the incentive for children of educated workers to become educated. However, in an economy with low levels of education, the wage gap between educated and uneducated workers will be larger, and this will reduce the number of children of uneducated workers who get educated and increase the incentive for children of educated parents to remain in the class of educated workers. Hence, mobility between the two classes will be low. Therefore, the model generates a positive relationship between economic development and the degree of intergenerational mobility.

Another factor explaining earnings correlation is of psychological nature as parents could transmit their tastes and attitudes to their children so that they would end up taking the same economic decision as an adult (Mayer et al. 2004). Moreover, the standards of living of parents tend to be imitated by their direct descendants so that children develop aspirations, which affect positively the income correlation across generations (De la Croix and Michel 1999; Cox et al. 2004).

Finally, I would like to mention an issue related to intergenerational mobility, namely, the possibility of "reversals of fortune". This situation occurs when the transition matrix displays a value in each of its diagonal cells that is lower than 0.5 . Therefore, in this case individuals belonging to the same dynasty will tend to change their status across generations. As we will see later on, it is possible to generate extreme oscillations of income across generations by taking into account the interaction between wealth and effort along the lines of the Carnegie conjecture. According to this conjecture, richer individuals tend to exert less effort in their occupations, which may result in turn in sudden falls in family wealth.

In the next three sections I am going to discuss in more detail three mechanisms driving the intergenerational transmission of socioeconomic status: borrowing constraints preventing purchases of human capital through education, transmission of tastes through aspiration formation, and the interaction between wealth and effort so as to generate reversals of family fortune.

\section{Borrowing constraints and investment in human capital}

Borrowing constraints make the long-run joint distribution of both human and physical capital in the economy dependent on the initial distribution of these two types of capital across individuals. As I have already pointed out, those constraints could give raise to the perpetuation of poverty of a family and, hence, they are an obvious impediment for intergenerational mobility. Let us consider a simple non-stochastic model following the lines of Alonso-Carrera et al. (2012) to illustrate the enhanced history dependence brought about by borrowing constraints. 


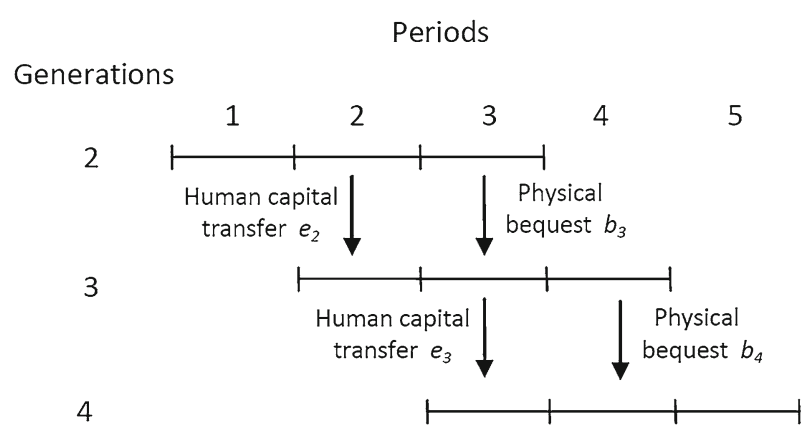

Fig. 3 Transfers within a family. (Source: Alonso-Carrera et al. 2012)

The economy I consider is populated by families whose members live for three periods. In the first period they can acquire human capital but this decision is taken by their parents through education expenditures. In the second period they work using the human capital acquired in the previous period and in the third period they are retired. The model has two main features borrowed from Galor and Zeira (1993) and many other authors: (i) the investment in human capital is indivisible, i.e., there is a minimum amount of investment in education and (ii) the capital market is imperfect due to the presence of borrowing constraints so that those individuals with a wealth level below some threshold can not afford the cost of education. Therefore, the initial distribution of wealth will determine the number of individuals that can acquire education and, thus, the aggregate stock of human capital in the next period. Let us assume that intergenerational transfers can take two forms: transfers of physical capital by means of bequests and transfers of human capital by means of the parents' investment in the education of their children. Generations are indexed by the period in which their members work (second period of life). Figure 3 summarizes the timing of transfers within a dynasty.

A generic individual belonging to the dynasty (or family) $i$ and working in period $t$ derives utility both from her consumption $c_{t}^{i}$ when she works (second period of her life), her consumption $x_{t+1}^{i}$ when she is retired (third period of her life) and her contribution $I_{t+1}^{i}$ to the lifetime income of her children (as in Becker and Tomes 1986). The preferences of an individual belonging to dynasty $i$ and to generation (adult in period) $t$ are represented by the following logarithmic utility function:

$$
U_{t}^{i}=\ln c_{t}^{i}+\beta \ln x_{t+1}^{i}+\rho \ln I_{t+1}^{i}, \quad \text { with } \beta>0 \text { and } \rho>0,
$$

where

$$
I_{t+1}^{i}=w \Delta_{t+1}^{i}+b_{t+1}^{i}
$$

and $w$ is the exogenous wage per unit of human capital, $b_{t+1}^{i}$ is the amount of physical bequest left to each descendant and $\Delta_{t+1}^{i}$ is the increase in the units of human capital resulting from the investment made in the education of her offspring. I assume that the number of children per individual is exogenous and equal to $n>0$. 
The level of human capital at period $t+1$ of an adult individual of dynasty $i$ is given by

$$
h_{t+1}^{i}=1+\Delta_{t+1}^{i}
$$

with

$$
\Delta_{t+1}^{i}= \begin{cases}0 & \text { if } e_{t}^{i}<\mu \\ \varepsilon & \text { if } e_{t}^{i} \geq \mu\end{cases}
$$

where $e_{t}^{i}$ is the amount invested in education, $\varepsilon>0$ is the education premium measured in units of human capital, and $\mu>0$ is the fixed cost of education. Obviously, the optimal investment in education for the individuals who want to have children with $h_{t+1}^{i}=1$ is $e_{t}^{i}=0$, whereas those individuals that want educated children (with $h_{t+1}^{i}=1+\varepsilon$ ) will choose $e_{t}^{i}=\mu$.

The budget constraint faced by an adult individual of dynasty $i$ in period $t$ is

$$
w_{t} h_{t}^{i}+b_{t}^{i}=c_{t}^{i}+s_{t}^{i}+n e_{t}^{i}
$$

and the budget constraint of an old individual of dynasty $i$ in period $t+1$ will be

$$
R s_{t}^{i}=x_{t+1}^{i}+n b_{t+1}^{i},
$$

where $R$ is the exogenous gross return on capital. Finally, I also impose the constraint that parents cannot force their children to give them gifts when the parents are old as there are neither contracts nor institutions to enforce reverse transfers,

$$
b_{t+1}^{i} \geq 0 \text {. }
$$

Note that negative voluntary bequests will never arise in equilibrium given our assumption of one-sided (from parents to children) altruism.

The bequest left to each of her descendants by an old individual belonging to family $i$ in period $t+1$ will depend on the inheritance $b_{t}^{i}$ she has received, her level $h_{t}^{i}$ of human capital and the investment $e_{t}^{i}$ in education she has made in their children when she was a worker,

$$
b_{t+1}^{i} \equiv B\left(b_{t}^{i}, h_{t}^{i}, e_{t}^{i}\right)
$$

If $b_{t+1}^{i}>0$, then it can be proved that this bequest function is given by the following linear function

$b_{t+1}^{i} \equiv B\left(b_{t}^{i}, h_{t}^{i}, e_{t}^{i}\right)=\left[\frac{\beta R}{n(1+\beta+\rho)}\right]\left(w h_{t}^{i}+b_{t}^{i}-n e_{t}^{i}\right)-\left[\frac{1+\rho}{1+\beta+\rho}\right] w \Delta_{t+1}^{i}$.

I am also going to impose the condition that education is always profitable,

$$
w \varepsilon \geq \mu R
$$

This condition simply states that the future increase in labor earnings of children due to the investment in education is larger than the capitalized cost of education. Obviously 
if condition (1) holds, individuals will invest in the education of their offspring if they can afford the minimum cost $\mu$ of education. Note that a positive investment in education for individuals with low levels of wealth could imply a negative amount of bequest, which is a situation that I have already ruled out by assumption. Therefore, in this case, the individuals will not invest in the education of their children even if the profitability condition (1) holds. The dynamics of human capital within a dynasty is given by the following dynamic equation:

$$
h_{t+1}^{i}=\left\{\begin{array}{l}
1 \text { if either } h_{t}^{i}=1 \text { and } 0 \leq b_{t}^{i}<\widetilde{b}^{0} \text { or } h_{t}^{i}=1+\varepsilon \text { and } 0 \leq b_{t}^{i}<\widehat{b}^{0} \\
1+\varepsilon \text { if either } h_{t}^{i}=1 \text { and } b_{t}^{i} \geq \widetilde{b}^{0} \text { or } h_{t}^{i}=1+\varepsilon \text { and } b_{t}^{i} \geq \widehat{b}^{0}
\end{array}\right.
$$

The following equation characterizes the dynamics of bequests within a dynasty:

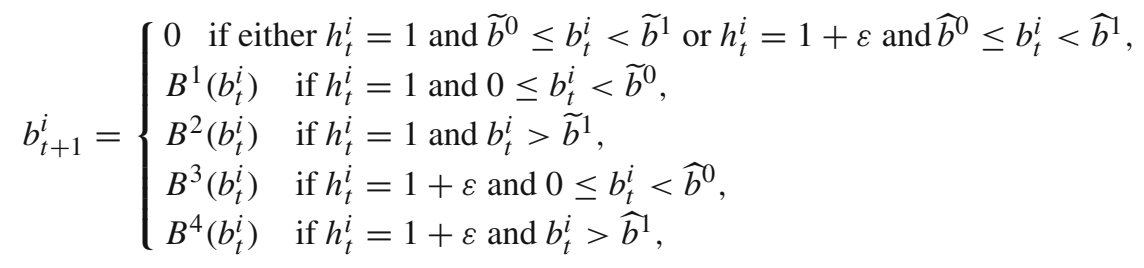

where $B^{1}\left(b_{t}^{i}\right) \equiv B\left(b_{t}^{i}, 1,0\right), B^{2}\left(b_{t}^{i}\right) \equiv B\left(b_{t}^{i}, 1, \mu\right), B^{3}\left(b_{t}^{i}\right) \equiv B\left(b_{t}^{i}, 1+\varepsilon, 0\right)$, and $B^{4}\left(b_{t}^{i}\right) \equiv B\left(b_{t}^{i}, 1+\varepsilon, \mu\right)$. The threshold levels $\widetilde{b}^{0}, \widehat{b}^{0}, \widetilde{b}^{1}, \widehat{b}^{1}$ appearing in the previous dynamic equations depend on the parameters of the model and satisfy $\widetilde{b}^{j}>\widehat{b}^{j}$, $j=0,1$. Therefore, the function (2) tells us that poor individuals cannot invest in the education of their children so that their descendants will have a human capital level equal to 1 , while rich individuals will endow their children with a level of capital equal to $1+\varepsilon$. The threshold level of inherited wealth above which the investment in education takes place is obviously higher for the unskilled parents than for the skilled ones since skilled parents will enjoy higher labor earnings. Under some plausible assumptions concerning the return on capital $R$, the wage per efficiency unit $w$, the school premium $\varepsilon$ and the cost of education $\mu$, the situation depicted in Fig. 4 concerning the bequest functions arises. ${ }^{3}$

We see from Fig. 4 that the initial distribution of bequests and human capital determines both the wealth distribution in the long run and the degree of intergenerational mobility in human capital. Families with an initial low level of human capital, $h_{0}^{i}=1$, will converge: (i) to the steady state with $h^{i}=1$ and $b^{i}=\bar{b}^{1}$ if $b_{0}^{i}<\widetilde{b}^{0}$; and (ii) to the steady state $h^{i}=1+\varepsilon$ and $b^{i}=\bar{b}^{2}$ if $b_{0}^{i}>\widetilde{b}^{0}$. Families with an initial high level of human capital $h_{0}^{i}=1+\varepsilon$ will always converge to the steady state $h^{i}=1+\varepsilon$ and $b^{i}=\bar{b}^{2}$. Therefore only the non-educated families may experience upward intergenerational mobility. In particular, the families with an initial level of human capital

\footnotetext{
3 These assumptions generate an equilibrium where transfers of human capital and physical wealth are positively related so that rich parents leave simultaneously large bequests and have educated offspring, which is consistent with the empirical evidence (Nordblom and Ohlsson 2011).
} 


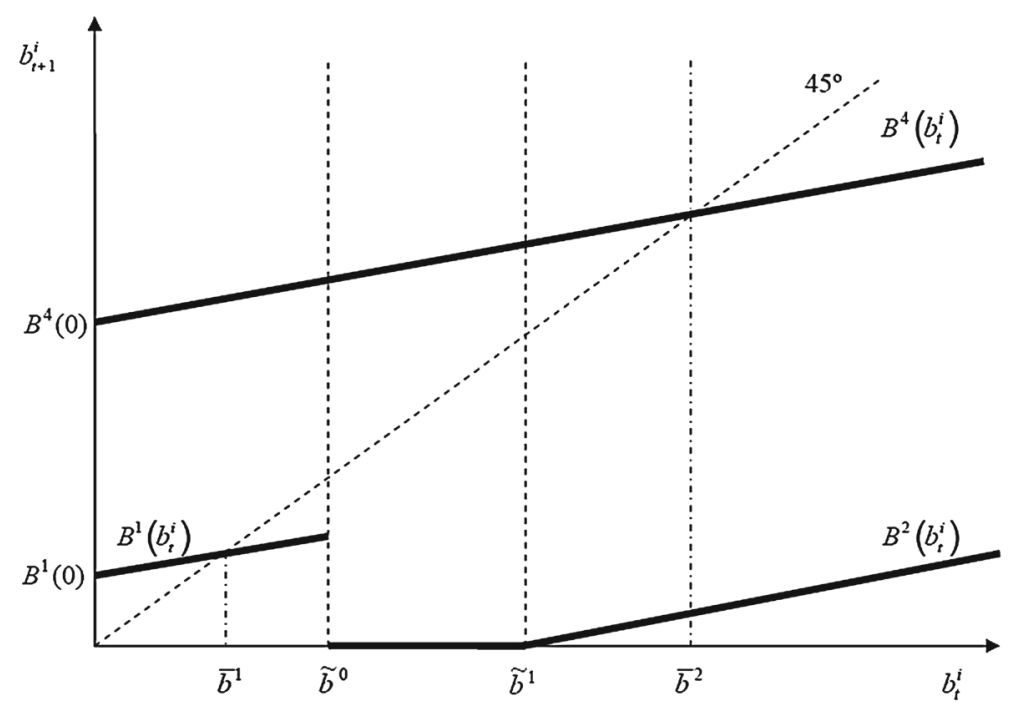

Fig. 4 The dynamics of bequests within a dynasty. (Source: Alonso-Carrera et al. 2012)

$h_{0}^{i}=1$ educate their children if $b_{0}^{i}>\widetilde{b}^{0}$, and then they will remain as educated families forever. Note that the threshold amount of bequest $\widetilde{b}^{0}$ contains all the information about the determinants of this one-shot upward mobility. The situation that emerges in this economy can be summarized in the following long-run transition matrix:

\begin{tabular}{lllll}
\hline Father & \multicolumn{3}{c}{ Son } \\
\cline { 2 - 5 } & R-S & P-S & R-U & P-U \\
\hline Rich-Skilled & 1 & 0 & 0 & 0 \\
Poor-Skilled & 1 & 0 & 0 & 0 \\
Rich-Unskilled & 1 & 0 & 0 & 0 \\
Poor-Unskilled & 0 & 0 & 0 & 1 \\
\hline
\end{tabular}

Transition matrix in the long-run

Therefore, families whose members at a given period are rich skilled, poor skilled or rich unskilled will eventually converge to the class of rich skilled. However, the poor unskilled families will keep their socioeconomic status forever. Thus, unskilled families with initial inherited wealth below the threshold $\widetilde{b}^{0}$ are the ones that face a poverty trap. Fiscal policy can thus affect the proportion of families that converge to each of the two steady states by distorting the intergenerational mobility in human capital through a variation in the threshold value $\widetilde{b}^{0}$.

Let us consider a marginal change in a particular instrument of fiscal policy that directly affects the equilibrium amount of bequests, namely, inheritance taxation. Let us assume that the amount of inheritance an individual receives is now taxed and the revenues are devoted to useless government consumption. Obviously, the marginal introduction of inheritance taxes will make physical bequests more costly as 


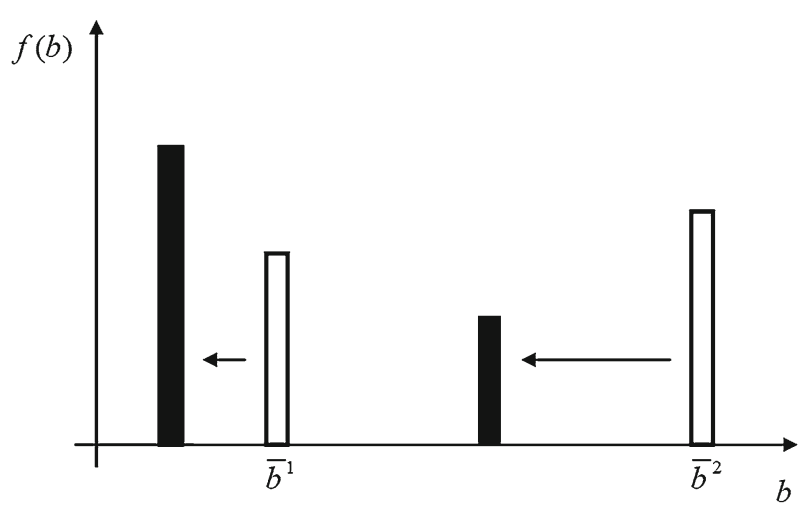

Fig. 5 The effect on the distribution of bequests of a marginal rise in the inheritance tax. (Source: AlonsoCarrera et al. 2012)

an instrument to increase the lifetime income of children so that the inheritance tax reduces the amount of bequest that parents leave to their offspring. Furthermore, this new tax raises the amount of pre-tax inheritance that an individual must receive from his parents in order to be willing to invest in the education of their children. Therefore, a marginal increase in the inheritance tax ends up being an impediment for upward mobility as the reduction in initial wealth prevents a larger fraction of individuals from jumping the hurdle associated with the indivisible cost of education. Figure 5 depicts the change in the relative long-run frequencies of the two steady states of the economy after introducing a tax on inheritance. These two steady states are the one of rich-skilled individuals (with an equilibrium amount of bequest equal to $\bar{b}^{2}$ ) and the one of poor-unskilled individuals (with an equilibrium amount of bequest equal to $\bar{b}^{1}$ ). The marginal introduction of inheritance taxation reduces the amount of bequest for both skilled and unskilled individuals and lowers the relative frequency of skilled individuals.

Another natural policy in this economic environment is the marginal introduction of an education subsidy, which directly distorts the decision of investing in education. As before, this subsidy will be financed by the corresponding adjustments in the amount of government consumption. The subsidy on education lowers the cost of education faced by individuals and thus reduces the amount of inheritance that they must receive to pay for the cost of education of their children. This will decrease the fraction of individuals who cannot afford the cost of education. However, the steady-state level of bequest $\bar{b}^{2}$ left by each rich educated individual will go up since she will benefit from the subsidy, whereas the level of bequests $\bar{b}^{1}$ left by non-educated (i.e., the poorest) individuals will not change since they do not invest in education and thus they are not entitled to benefit from the subsidy. Therefore, the resulting situation involves a larger gap between the wealth of rich and poor individuals as a consequence of the marginal introduction of this education subsidy. Figure 6 shows the corresponding change in the histogram of long-run frequencies.

The previous model has shown that not only the initial distribution of wealth, but also the distribution of the composition of wealth between bequests (i.e., initial physical 


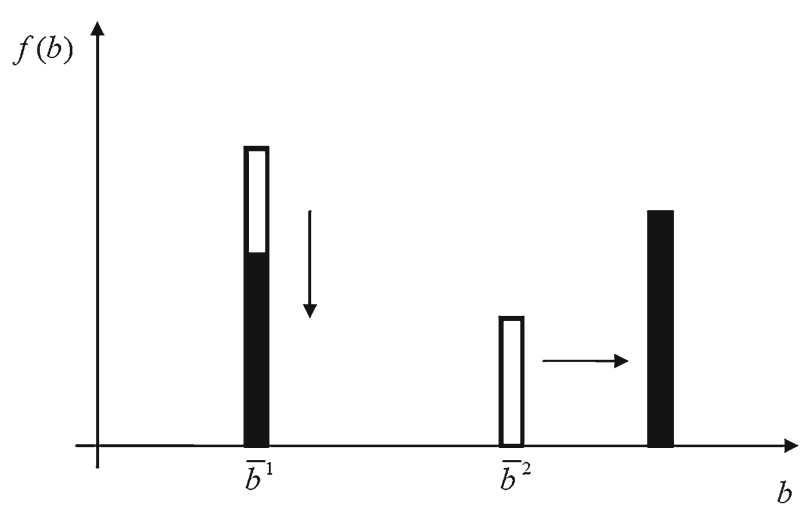

Fig. 6 The effect on the distribution of bequests of a marginal increase in the education subsidy. (Source: Alonso-Carrera et al. 2012)

wealth) and human capital, are important to characterize the degree of intergenerational mobility in socioeconomic status. Moreover, the previous model suggests that differences in intergenerational mobility across countries could be explained by differences in the initial distribution and composition of wealth, in the fiscal policy set by the governments, in the degree of imperfection of the credit market and in education cost.

\section{Transmission of tastes and wealth persistence}

In this section I will show through a simple model based on Caballé and Moro-Egido (2014) how the introduction of intergenerational transmission of preferences affects dynastic mobility in the values of relevant economic variables. The simplest way of generating intergenerational transmission of tastes is through the introduction of aspirations, that is, by assuming that an individual's utility depends on a comparison between his current amount of consumption and that of his parents. In other words, the amount of consumption of parents determines the standard of living with respect which current own consumption is compared to.

Let us consider an overlapping generations framework like that of the previous section, where individuals live for three period but only make economic decisions in the last two period of their life. Here, in the first period individuals will only observe the level of consumption of their parents, who are in the second period of their lives. The individual $i$ belonging to the generation $t$ derives utility from the aspiration adjusted adult consumption $\hat{c}_{t}^{i}$, old consumption $x_{t+1}^{i}$ and the amount $b_{t+1}^{i}$ of bequests left to each direct descendant. I am thus assuming a motive for bequest based on "joy-ofgiving" or "warm-glow altruism" like in Yaari (1965) and Abel (1986). The utility function is assumed to have the following functional form:

$$
U\left(\hat{c}_{t}^{i}, x_{t+1}^{i}, b_{t+1}^{i}\right)=\ln \left(\hat{c}_{t}^{i}\right)+\beta \ln \left(x_{t+1}^{i}\right)+\rho \ln \left(b_{t+1}^{i}\right), \quad \text { with } \beta>0 \text { and } \rho>0 .
$$

The inherited aspiration of an individual $i$ of generation $t$ is $a_{t}^{i}=c_{t-1}^{i}$, where $c_{t-1}^{i}$ is his parent's amount of consumption when the parent was an adult (second period of 
life). I assume an additive specification for the aspiration adjusted consumption $\hat{c}_{t}^{i}$ of an adult individual $i$ in period $t$ :

$$
\hat{c}_{t}^{i}=c_{t}^{i}-\gamma a_{t}^{i}=c_{t}^{i}-\gamma c_{t-1}^{i}, \quad \text { with } \gamma \in[0,1)
$$

which means that, for the same level of consumption $c_{t}^{i}$ of an individual $i$, the utility decreases with the level of consumption of his parent since this means that the individual has developed greater aspirations. Moreover, this specification implies that the marginal utility of aspiration adjusted consumption is increasing in the amount of aspirations (i.e., of parental consumption). I assume a constant interest factor $R$ and idiosyncratic productivity shocks on labor that make wages $w_{t}^{i}$ identically and independently distributed (i.i.d.) across individuals and across time. The expectation and the variance of wages are assumed to be equal to $\bar{w}$ and $\sigma^{2}$, respectively, for all individuals and periods. Finally, I assume that this shock in labor income is not insurable. The budget constraints faced by the individual $i$ who is adult (worker) in period $t$ are

$$
w_{t}^{i}+b_{t}^{i}=c_{t}^{i}+s_{t}^{i}
$$

and

$$
R s_{t}^{i}=x_{t+1}^{i}+n b_{t+1}^{i},
$$

where $s_{t}^{i}$ is the amount of saving and $n$ is the number of children per parent.

The solution to the previous individual problem delivers the following linear demand functions for consumptions, bequest, and saving in equilibrium:

$$
\begin{gathered}
c_{t}^{i}=A\left(w_{t}^{i}+b_{t}^{i}\right)+B a_{t}^{i}=A\left(w_{t}^{i}+b_{t}^{i}\right)+B c_{t-1}^{i}, \\
x_{t+1}^{i}=C\left(w_{t}^{i}+b_{t}^{i}\right)-D a_{t}^{i}=C\left(w_{t}^{i}+b_{t}^{i}\right)-D c_{t-1}^{i}, \\
b_{t+1}^{i}=E\left(w_{t}^{i}+b_{t}^{i}\right)-F a_{t}^{i}=E\left(w_{t}^{i}+b_{t}^{i}\right)-F c_{t-1}^{i},
\end{gathered}
$$

and

$$
s_{t}^{i}=G\left(w_{t}^{i}+b_{t}^{i}\right)-B a_{t}^{i}=G\left(w_{t}^{i}+b_{t}^{i}\right)-B c_{t-1}^{i},
$$

where

$$
\begin{aligned}
A & =\frac{1}{1+\beta+\rho}, \quad B=\frac{\delta(\beta+\rho)}{1+\beta+\rho}, \\
C & =\frac{\beta R}{1+\beta+\rho}, \quad D=\frac{\delta R \beta}{1+\beta+\rho}, \\
E & =\frac{\rho R}{n(1+\beta+\rho)}, \quad F=\frac{\delta \rho R}{n(1+\beta+\rho)}, \\
G & =\frac{\beta+\rho}{1+\beta+\rho} .
\end{aligned}
$$

From the system formed by Eqs. (3) and (4) and, assuming that there is a continuum of dynasties with unitary mass and that the strong law of large numbers holds in 
this economy, I can compute the equations that drive the evolution of the different empirical moments of the joint distribution of the amount $c_{t}$ of adult consumption and the amount $b_{t+1}$ of bequests left by the generation that is adult in period $t$. In particular, the following two difference equations, which are obtained by just taking expectations on both sides of Eqs. (3) and (4), characterize the evolution of average young consumption $\bar{c}_{t}$ and average bequest $\bar{b}_{t+1}$,

$$
\bar{c}_{t}=B \bar{c}_{t-1}+A \bar{b}_{t}+A \bar{w}
$$

and

$$
\bar{b}_{t+1}=-F \bar{c}_{t-1}+E \bar{b}_{t}+E \bar{w} .
$$

Note that from the evolution of the averages $\bar{c}_{t}$ and $\bar{b}_{t+1}$ we can obtain the dynamics of average savings $\bar{s}_{t}$ by just using (5),

$$
\bar{s}_{t}=-B \bar{c}_{t-1}+G \bar{b}_{t}+G \bar{w} .
$$

Similarly, computing the variances in both sides of (3) and (4) and the covariance between these two equations, we get the following three difference equations driving the dynamic evolution of the empirical variances of adult consumption, $\operatorname{Var}\left(c_{t}\right)$, and bequests, $\operatorname{Var}\left(b_{t+1}\right)$, and the covariance $\operatorname{Cov}\left(c_{t}, b_{t+1}\right)$ between these two variables:

$$
\begin{aligned}
\operatorname{Var}\left(c_{t}\right) & =B^{2} \operatorname{Var}\left(c_{t-1}\right)+A^{2} \operatorname{Var}\left(b_{t}\right)+2 A B \operatorname{Cov}\left(c_{t-1}, b_{t}\right)+A^{2} \sigma^{2}, \\
\operatorname{Var}\left(b_{t+1}\right) & =F^{2} \operatorname{Var}\left(c_{t-1}\right)+E^{2} \operatorname{Var}\left(b_{t}\right)-2 E F \operatorname{Cov}\left(c_{t-1}, b_{t}\right)+E^{2} \sigma^{2},
\end{aligned}
$$

and

$$
\begin{aligned}
& \operatorname{Cov}\left(c_{t}, b_{t+1}\right)=-B F \operatorname{Var}\left(c_{t-1}\right)+A E \operatorname{Var}\left(b_{t}\right) \\
& +(B E-A F) \operatorname{Cov}\left(c_{t-1}, b_{t}\right)+A E \sigma^{2} .
\end{aligned}
$$

Again, the dynamics of the variance of saving is obtained from the previous second moments since (5) implies the following relationship:

$$
\operatorname{Var}\left(s_{t}\right)=G^{2} \operatorname{Var}\left(b_{t}\right)+B^{2} \operatorname{Var}\left(c_{t-1}\right)-2 B G \operatorname{Cov}\left(c_{t-1}, b_{t}\right)+G^{2} \sigma .
$$

The previous expressions make explicit how the first two empirical moments of consumption and bequests of a given cohort affect the empirical moments of the following cohort. In order to obtain monotonic convergence both for the first moments of the distribution, which are governed by the system of difference Eqs. (6) and (7), and for the second moments, which are governed by the system of difference Eqs. (8), (9), and (10), we need to impose standard stability assumptions found in capital accumulation models, namely, that the bequest motive $\rho$ is sufficiently low and the gross rate $n$ of population growth is sufficiently high so as to prevent per capita bequests to grow without bound. Moreover, we also need to assume that the aspiration intensity $\delta$ is sufficiently low. If $\delta$ is very large then the economy could exhibit cycles (see De la Croix and Michel 1999). To understand the emergence of cycles for large aspiration 
intensities consider a non-stochastic environment and a generation that consumes a lot due to an aspirational motive (i.e., to achieve the same standard of living of their parents when adult). This will result in a reduction in the amount left as bequests, which in turn will reduce the life-time income and thus the consumption of the next generation. Therefore, intergenerational oscillations of consumption will naturally arise.

I can perform now the analysis of the effects of aspirations on the degree of intergenerational mobility in this economy. I can study mobility in consumption at different ages, bequests or savings but I am going to focus my analysis just on mobility in savings (or wealth), that is, in the amount of asset holdings accumulated by individuals before entering into retirement.

The amount of savings $s_{t+1}^{i}$ of the direct descendent of an individual $i$ belonging to generation $t$ is

$$
\begin{aligned}
s_{t+1}^{i} & =G w_{t+1}^{i}+G b_{t+1}^{i}-B c_{t}^{i} \\
& =G w_{t+1}^{i}+G \underbrace{\left(E w_{t}^{i}+E b_{t}^{i}-F c_{t-1}^{i}\right)}_{b_{t+1}^{i}}-B \underbrace{\left(A w_{t}^{i}+A b_{t}^{i}+B c_{t-1}^{i}\right)}_{c_{t}^{i}},
\end{aligned}
$$

as follows from (3), (4), and (5). We see that the intergenerational transmission of wealth arises from two channels: bequests $b_{t+1}^{i}$ and parental consumption $c_{t}^{i}$. Moreover, the saving of the parent of this individual is given by (5). Therefore, making use of the strong law of large numbers and the stability assumption, we can measure the degree of mobility in the long-run by using the steady-state value of the intergenerational correlation $I C$ of asset holdings between two successive generations as in Bossmann et al. (2007),

$$
I C \equiv \lim _{t \rightarrow \infty} \frac{\operatorname{Cov}\left(s_{t+1}^{i}, s_{t}^{i}\right)}{\left(\operatorname{Var}\left(s_{t+1}^{i}\right)\right)^{1 / 2} \cdot\left(\operatorname{Var}\left(s_{t}^{i}\right)\right)^{1 / 2}}=\lim _{t \rightarrow \infty} \frac{\operatorname{Cov}\left(s_{t+1}, s_{t}\right)}{\operatorname{Var}\left(s_{t}\right)}=\frac{\operatorname{Cov}\left(s^{\prime}, s\right)}{\operatorname{Var}(s)}
$$

where the variables with prime refer to next period variables. As we saw in Sect. 2, the higher is the value of $I C$, the lower is the degree of intergenerational wealth mobility. Note that with no bequests and no aspirations there is complete mobility, $I C=0$, as the fluctuation of savings will be driven exclusively by the i.i.d. process of wages. Conversely, if we had perfect correlation of asset holdings, i.e., $I C=1$, then intergenerational wealth mobility would be null.

Using (5) and (12) we can easily compute the covariance between savings of parents and sons,

$$
\begin{aligned}
\operatorname{Cov}\left(s_{t+1}^{i}, s_{t}^{i}\right)= & G H \sigma^{2}+G H \operatorname{Var}\left(b_{t}^{i}\right)-G I \operatorname{Cov}\left(c_{t-1}^{i}, b_{t}^{i}\right)-B H \operatorname{Cov}\left(c_{t-1}^{i}, b_{t}^{i}\right) \\
& +B I \operatorname{Var}\left(c_{t-1}^{i}\right),
\end{aligned}
$$

where

$$
H=E G-A B, \quad \text { and } \quad I=B^{2}+F G .
$$


Therefore, using the strong law of large numbers, we can compute the empirical serial covariance of wealth,

$\operatorname{Cov}\left(s_{t+1}, s_{t}\right)=G H\left(\sigma^{2}+\operatorname{Var}\left(b_{t}\right)\right)+B I \operatorname{Var}\left(c_{t-1}\right)-(B H+G I) \operatorname{Cov}\left(c_{t-1}, b_{t}\right)$,

and the corresponding steady-state value of this covariance is thus

$$
\operatorname{Cov}\left(s^{\prime}, s\right)=G H\left(\sigma^{2}+\operatorname{Var}(b)\right)+B I \operatorname{Var}(c)-(B H+G I) \operatorname{Cov}\left(c, b^{\prime}\right),
$$

where $\operatorname{Var}(c), \operatorname{Var}(b)$, and $\operatorname{Cov}\left(c, b^{\prime}\right)$ are the steady-state second moments of the distribution of adult consumption and bequest, which under the stability assumptions I have made, coincide with their long-run values. Similarly, from (11) we get the steady-state variance of saving

$$
\operatorname{Var}(s)=G^{2} \operatorname{Var}(b)+B^{2} \operatorname{Var}(c)-2 B G \operatorname{Cov}\left(c, b^{\prime}\right)+G^{2} \sigma .
$$

Therefore, we have all the elements needed to compute the long-run intergenerational wealth correlation given in (13).

The parameter $\delta$ measuring the intensity of aspirations enters in the coefficients $B$ and $F$ (and thus in $H$ and $I$ ) and in the steady-state equilibrium values of $\operatorname{Var}(b)$, $\operatorname{Var}(c)$, and $\operatorname{Cov}\left(c, b^{\prime}\right)$. This results in a very complex equation relating the $I C$ with the aspiration intensity $\delta$. However, it can be proved that the marginal introduction of aspirations ends up reducing the value of $I C$ so that the degree of mobility in wealth increases. The intuition behind this result lies in the fact that the marginal utility of adult consumption increases when aspirations are introduced and, thus, workers tend to increase their consumption by reducing both their saving and the amount of bequests they leave to their children. Obviously, this results in a smaller correlation between the assets of parents and their direct descendants.

One interesting by-product of this model is that the presence of warm-glow altruism gives raise to a positive amount of bequests and, hence, it opens the door to positive persistence in asset holdings within a dynasty. If there were no bequests in our economy, which occurs when the bequest motive is $\rho=0$, the intergenerational correlation $I C$ of asset holdings would be negative. Obviously, when aspirations are present in an economy with no altruism, adult individuals seek to mimic the consumption level of their parents and, since labor income is uncorrelated across generations, the savings of two consecutive members of the same family would become negatively correlated.

\section{On the possibility of reversals of fortune and the Carnegie conjecture}

I have already mentioned in the previous section that the presence of aspirations might be a source of deterministic endogenous cycles in asset holdings across successive generations of a given dynasty. This means that the economic system has inherent forces that make individual wealth to fluctuate so that rich parents are followed by poor sons and vice versa. These wealth oscillations take thus the form of endogenous reversals 
of fortune, which are just driven by the intergenerational transmission of tastes about consumption. In this economic environment the supply of efficiency units of labor is assumed to be exogenous and, thus, it plays no role for the emergence of cycles.

The possibility of the aforementioned reversals of fortune and, therefore, of deterministic intergenerational mobility has been analyzed by several authors through the lenses of the so called "Carnegie conjecture" according to which "the parent who leaves his son enormous wealth generally deadens the talents and energies of the son, and tempts him to live a less useful and less worthy life than he otherwise would ..." (Carnegie 1962). There is some empirical evidence about the negative relationship between the amount of inheritance individuals receive and their labor supply. The reduction in the labor supply brought about by large bequests could take the form of a reduction in the number of hours worked, an early retirement decision, or direct job quitting (see Brown et al. 2010; Cox 2014; Elinder et al. 2012; Erlend et al. 2012; Holtz-Eakin et al. 1993; Joulfaian and Wilhelm 1994, 2006). This reduction in the effort put in production activities typically results in a reduction in the amount of wealth transmitted to the next generation.

Degan and Thibault (2016) have modeled explicitly the Carnegie conjecture in a non-stochastic model where the amount of effort (and thus of labor income) depends on the endogenous amount of inheritance individuals receive. Rich individuals have less incentives to exert effort since the increase in marginal utility arising from higher labor income for the rich individuals is lower than for the poor. Under some assumptions about the parameter values concerning the bequest motive and the cost of effort, these authors generate patterns of dynastic accumulation of wealth displaying a deterministic strong mobility in family wealth. This strong mobility agrees with the studies reported by Cochell and Zeeb (2005), according to which six out of ten very rich families lose the family fortune by the end of the second generation and nine out of ten will loose it by the end of the third generation.

The models of Doepke and Zilibotti (2008) and Gradstein (2008) assume instead that parents shape the preferences of their children concerning the effort they devote to their work. Doepke and Zilibotti assume that the members of middle-class and poor families develop patience and a work ethic, which are the attitudes that better fit in their occupations, while the members of upper class families, who rely on large capital income, invest instead in the appreciation of leisure. Gradstein (2008) proposes an alternative mechanism of intergenerational transmission of preferences in which poor parents have incentives to provide their children with working habits to minimize children dependence on parental transfers. These two mechanisms of endogenous transmission of preferences give raise to strong fluctuations of wealth across generations and, thus, to reversals of fortune within a family.

Alonso-Carrera et al. (2016) propose a modification of the previous model by Degan and Thibault to explain simultaneously the reversals of fortune and the intergenerational persistence of education levels within families. This persistence of education attainment has been empirically documented by Hertz et al. (2008) and Behrman et al. (2001), who found a high correlation between years of schooling between fathers and their children in countries where the credit constraints to finance education are binding, as it occurs in many South American countries. However, Nordic countries display lower estimates of intergenerational education correlations (Chevalier et al. 
2009 and Hertz et al. 2008), which could be explained by the existence of a welfare state providing public education so that borrowing constraints become less relevant for human capital investment. The mechanism proposed by Alonso et al. is again based on the interaction between effort and wealth suggested by the Carnegie conjecture. They assume that individuals finance their own education when young using the wealth they have inherited from their parents and that exerting effort has a cost in terms of utility. They assume again that there is a minimum indivisible cost $\mu$ for acquiring education and that individuals cannot borrow to finance their education. Moreover, they assume that the wage compensation is an increasing function of both human capital (or skill) and effort made by workers. Finally, human capital and labor effort are assumed to be strong complements in the determination of wages. In other words, the return in terms of labor earning from effort is higher for the educated (or skilled) individuals than for the unskilled.

Under some assumptions about the wage as a function of skill and effort together with a restriction on the value $\mu$ of the education cost, it can be proved that only the individuals that have skilled parents can afford the indivisible cost of education since they are the ones who receive a sufficiently large inheritance to be spent in human capital acquisition. Moreover, the Carnegie conjecture applies both within the class of skilled families and within the class of unskilled families so that generations exerting effort are followed by generations that do not exert it. When an individual receives a large inheritance he exerts small effort so that the wealth of the family decreases. Since the next generation receives a small inheritance, their members make more effort and the wealth of the family increases again. Note that the amount of bequest left by a parent plays a triple role as it determines the initial wealth of his children, the skill level they will acquire through schooling, and the amount of effort they will exert. Finally, both effort and skill will determine in turn the initial amount of wealth of the next generation within the dynasty.

The previous mechanism generates a rich social class structure with four socioeconomic classes in the long-run: (1) A poor class composed of unskilled individuals who do not make effort; (2) a rich class composed of skilled individuals who exert effort; (3) a middle class composed of unskilled individuals who make effort; and (4) another middle class composed of skilled individuals who do not exert effort. Moreover, there is large mobility among classes in the long-run equilibrium as the economy displays both upward and downward mobility between the two classes of unskilled individuals and between the two classes of skilled individuals.

The long-run transition matrix among the four socioeconomic classes of the economy has the following structure, which generates two simultaneous deterministic cycles for both skilled and unskilled dynasties:

\begin{tabular}{llllc}
\hline Father & \multicolumn{3}{c}{ Son } \\
\cline { 2 - 5 } & R-S & P-S & R-U & P-U \\
\hline Rich-Skilled & 0 & 1 & 0 & 0 \\
Poor-Skilled & 1 & 0 & 0 & 0 \\
Rich-Unskilled & 1 & 0 & 0 & 1 \\
Poor-Unskilled & 0 & 0 & 1 & 0 \\
\hline
\end{tabular}

Transition matrix displaying two cycles 


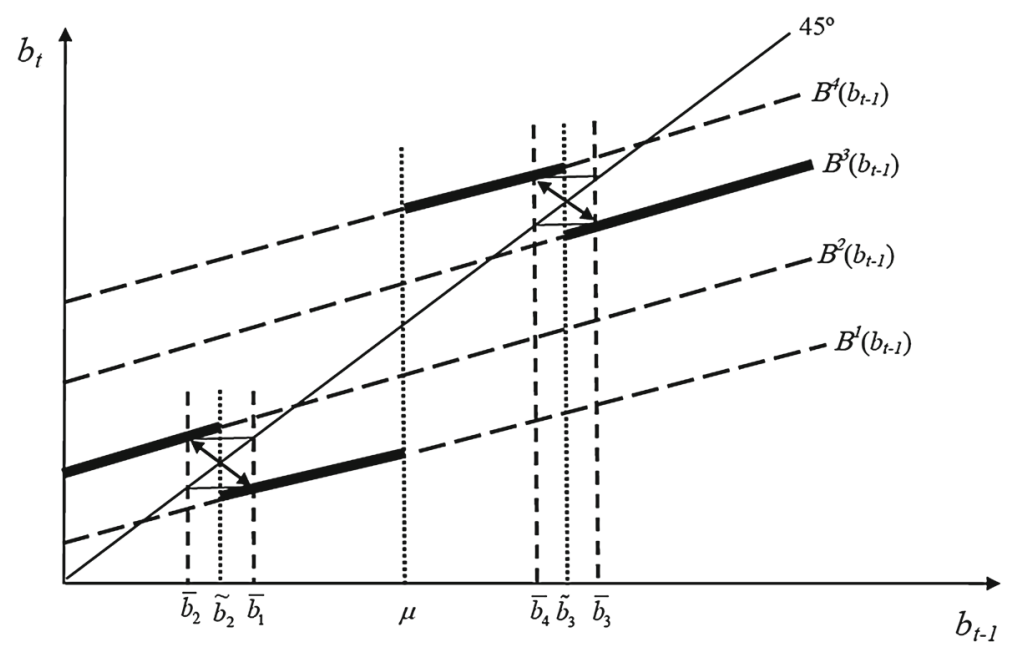

Fig. 7 Cycles in the amount of bequest for skilled and unskilled families. (Source: Alonso-Carrera et al. 2016)

Figure 7 depicts the resulting equilibrium in the long-run. In this equilibrium, the educated families are in a cycle where generations that exert no effort and leave an amount of bequest equal to $\bar{b}_{4}$ alternate with generations that make effort and leave a bequest equal $\bar{b}_{3}$. The non-educated dynasties are also in a cycle where generations that do not exert effort and leave an amount of bequest equal to $\bar{b}_{2}$ alternate with generations that make effort and leave a bequest equal to $\bar{b}_{1}$. Note that the value $\mu$ of the education cost is such that the skilled dynasties remain skilled forever and the same occurs for the unskilled dynasties. Therefore, the model gives raise to mobility in wealth levels but high persistence in education attainment across generations. Moreover, the model displays the realistic feature that unskilled individuals get uniformly smaller bequests than skilled individuals.

Finally, it should be emphasized that the existence of the rich social class structure and the corresponding dynastic dynamics I have just described relies on particular exogenous values of the wage for different combinations of effort and skill and of the education cost. Therefore, changes in technology may induce variations in both the skill premium and the effort premium, which result in dramatic changes in the social structure. Similarly, changes in public policy may also make some social classes disappear. For instance, let us consider a reform in the welfare state so that the indivisible cost $\mu$ of education faced by individuals experiences a sizeable reduction. Figure 8 shows the situation emerging after this non-marginal policy change. The cycle involving educated individuals disappears and, hence, all the educated individuals end up not making effort. This is so because to exert effort is no longer necessary to preserve the skill level across individuals belonging to the same dynasty. Moreover, the size of the population that becomes educated increases since now the education becomes more affordable. 


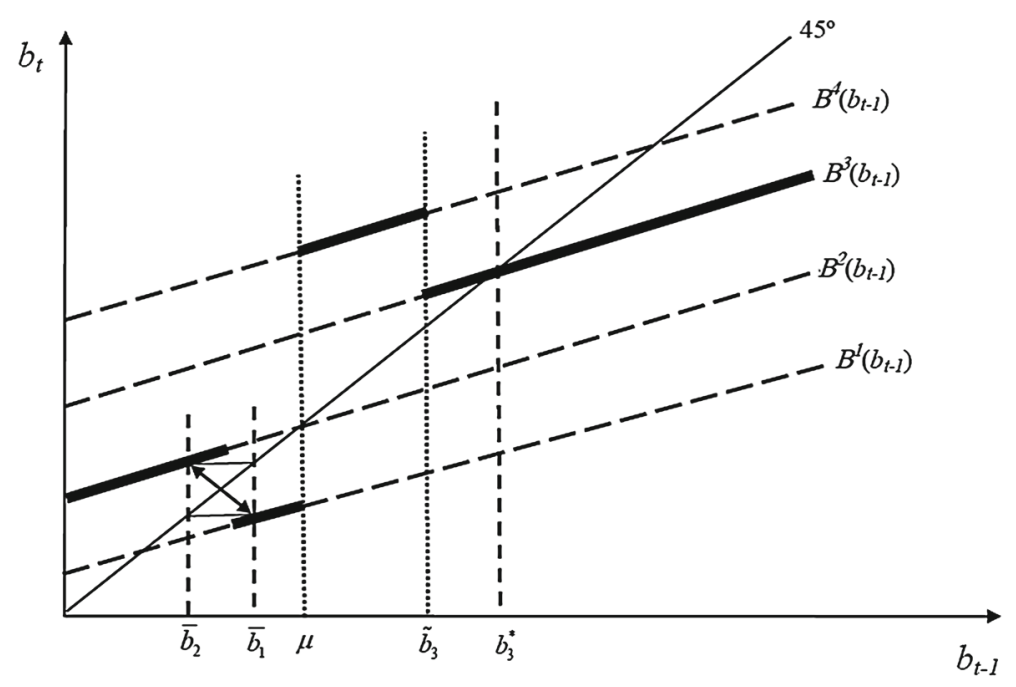

Fig. 8 Equilibria after a large reduction in the cost $\mu$ of education. (Source: Alonso-Carrera et al. 2016)

\section{Final remarks}

In this paper I have reviewed some measures of intergenerational mobility used in empirical economics and discussed some of the mechanisms explaining persistence of economic variables among the members of the same family across generations. I have put special emphasis on the role of aspirations in shaping the preferences of the members of a family and in the role of borrowing constraints in limiting the access to education. These two factors typically result in a smaller degree of intergenerational mobility. I have also tried to shed some light on the factors that could give raise to reversals of fortune within a family.

Since borrowing constraints result in the inability of families to make an optimal investment in education, I have analyzed the effects on intergenerational mobility of popular policy measures that are supposedly aimed at alleviating these constraints, like education subsidies or inheritance taxes. In this respect, I should stress that I have not delved into the normative consequences of the lack of intergenerational mobility and, therefore, I have not discussed either the welfare implications of specific public policies. A proper welfare analysis of the issues discussed in this paper will require the use of the appropriate social welfare measure for an economy populated with potentially altruistic individuals belonging to different generations. Moreover, I have not explored either the growth implications of an increase in the degree of intergenerational mobility arising from a better allocation of investments in education. However, I would like to emphasize the importance of these topics that I have left outside the focus of the paper since, at the end, the analysis of the factors that prevent intergenerational mobility and of the policies that enhance it is crucial for the promotion of societies where both equal opportunity and efficiency prevail. 
Open Access This article is distributed under the terms of the Creative Commons Attribution 4.0 International License (http://creativecommons.org/licenses/by/4.0/), which permits unrestricted use, distribution, and reproduction in any medium, provided you give appropriate credit to the original author(s) and the source, provide a link to the Creative Commons license, and indicate if changes were made.

\section{References}

Abel A (1986) Capital accumulation and uncertain lifetimes with adverse selection. Econometrica 54:1079_ 1097

Alonso-Carrera J, Caballé J, Raurich X (2012) Fiscal policy, composition of intergenerational transfers, and income distribution. J Econ Behav Organ 84:62-84

Alonso-Carrera J, Caballé J, Raurich X (2016) Intergenerational mobility under education-effort complementarity. Barcelona GSE Working paper 905

Becker G, Tomes N (1979) An equilibrium theory of the distribution of income and intergenerational mobility. J Political Econ 87:1153-1189

Becker G, Tomes N (1986) Human capital and the rise and fall of families. J Labor Econ 4:S1-S39

Behrman JR, Gaviria A, Székely M, Birdsall N, Galiani S (2001) Intergenerational mobility in Latin America. Economía 2:1-44

Behrman JR, Rosenzweig M (2004) Returns to birthweight. Rev Econ Stat 86:586-601

Bingley P, Christensen K, Jensen VM (2009) Parental schooling and child development: learning from twin parents. Danish National Centre for Social Research, Working paper 07

Black SE, Devereux PJ (2011) Recent developments in intergenerational mobility. In: Ashenfelter O, Card D (eds) Handbook of labor economics, vol 4B. Elsevier, Amsterdam, pp 1487-1542

Blanden J, Goodman A, Gregg P, Machin S (2004) Changes in intergenerational mobility in Britain. In: Corak M (ed) Generational income mobility in North America and Europe. Cambridge University Press, Cambridge, pp 122-146

Bossmann M, Kleiber C, Waelde K (2007) Bequests, taxation and the distribution of wealth in a general equilibrium model. J Public Econ 91:1247-1271

Brown JR, Coile CC, Weisbenner SJ (2010) The effect of inheritance receipt on retirement. Rev Econ Stat 92:425-434

Caballé J, Moro-Egido AI (2014) Effects of aspirations and habits on the distribution of wealth. Scand J Econ 116:1012-1043

Carnegie A (1962) The gospel of wealth and other timely essays. Harvard University Press, Cambridge

Cervini-Plá, M (2011) Intergenerational earnings and income mobility in Spain. Munich Personal RePEc Archive Paper 34942

Cervini-Plá M (2015) Intergenerational earnings and income mobility in Spain. Rev Income Wealth 61:812828

Chetty R, Hendren N, Kline P, Saez E (2014) Where is the land of opportunity? The geography of intergenerational mobility in the United States. Q J Econ 129:1553-1623

Chevalier A, Denny K, McMahon D (2009) A Multi-country study of inter-generational educational mobility. In: Dolton P, Asplundh R, Barth E (eds) Education and inequality across Europe. Edward Elgar, Cheltenham, pp 260-281

Cochell P, Zeeb R (2005) Beating the Midas Curse. Heritage Institute Press, West Linn

Corak M (2013) Inequality from generation to generation: The United States in comparison. In: Rycroft R (ed) The economics of inequality, poverty, and discrimination in the 21 st century, vol I. ABC-CLIO, pp 107-125

Cox D (2014) Inheritance, bequests, and labor supply. IZA World of Labor

Cox D, Ng S, Waldkirch A (2004) Intergenerational linkages in consumption behavior. J Hum Resour 32:355-381

Dahl MW, DeLeire T (2008) The association between children's earnings and fathers' lifetime earnings: estimates using administrative data. Institute for Research on Poverty, University of Wisconsin-Madison, Discussion paper 1342-08

De la Croix D, Michel P (1999) Optimal growth when tastes are inherited. J Econ Dyn Control 23:519-537

Degan A, Thibault E (2016) Dynastic accumulation of wealth. Math Soc Sci 81C:66-78

Doepke M, Zilibotti F (2008) Occupational choice and the spirit of capitalism. Q J Econ 123:747-793

Durlauf SN (1996) A theory of persistent income inequality. J Econ Growth 1:75-93 
Elinder M, Erixon O, Ohlsson H (2012) The impact of inheritances on heirs' labor and capital income. B.E. J Econ Anal Policy, vol 12, Article 61

Erlend EB, Halvorse E, Thoresen TO (2012) Inheritance as a disincentive to labor effort (Manuscript)

Galor O, Moav O (2004) From physical to human capital accumulation: inequality and the process of development. Rev Econ Stud 71:1001-1026

Galor O, Moav O (2006) Das human-kapital: a theory of the demise of the class-structure. Rev Econ Stud 73:85-117

Galor O, Zeira J (1993) Income distribution and macroeconomics. Rev Econ Stud 60:35-52

Gradstein M (2008) Endogenous reversals of fortune. IZA Discussion Paper 3469

Grawe ND, Mulligan C (2002) Economic interpretations of intergenerational correlations. J Econ Perspect $6: 45-58$

Hertz T, Jayasundera T, Piraino P, Selcuk S, Smith N, Verashchagina A (2008) The inheritance of educational inequality: international comparisons and fifty-year trends. B.E. J Econ Anal Policy, vol 7, Article 10

Holtz-Eakin D, Joulfaian D, Rosen HS (1993) The Carnegie conjecture: some empirical evidence. Q J Econ 108:413-435

Ichino A, Karabarbounis L, Moretti E (2011) The political economy of intergenerational income mobility. Econ Inq 49:47-69

Isaacs JB (2007) Economic mobility of families across generations. Brookings and Economic Mobility Project (The Pew Charitable Trusts) report

Jäntti M, Bratsberg B, Røed K, Raaum O, Naylor R, Österbacka E, Björklund A, Eriksson T (2006) American exceptionalism in a new light: a comparison of intergenerational earnings mobility in the Nordic countries, the United Kingdom and the United States. IZA Discussion paper 1938

Jäntti M, Jenkins SP (2015) Income mobility. In: Atkinson AB, Bourguignon F (eds) Handbook of income distribution, vol 2. Elsevier, Amsterdam, pp 807-935

Joulfaian D, Wilhelm MO (1994) Inheritance and labor supply. J Hum Resour 29:1205-1234

Joulfaian D, Wilhelm, MO (2006) Inheritance and saving. NBER Working paper 12569

Long J, Ferrie J (2013) Intergenerational occupational mobility in Great Britain and the United States since 1850. Am Econ Rev 103:1109-1137

Mayer SE, Duncan G, Kalil A (2004) Like mother, like daughter? SES and the intergenerational correlation of traits, behaviors and attitudes. Harris School of Public Policy Studies, University of Chicago, Working paper 0415

Mazumder B (2005) Fortunate sons: new estimates of intergenerational mobility in the U.S. using social security earnings data. Rev Econ Stat 87:235-255

Mazumder B (2008) Sibling similarities and economic inequality in the US. J Popul Econ 21:685-701

Nicoletti C, Ermisch J (2007) Intergenerational earnings mobility: changes across cohorts in Britain. B.E. J Econ Anal Policy, vol 7, Article 9

Nordblom K, Ohlsson H (2011) Bequests, gifts, and education: links between intergenerational transfers. Empir Econ 40:343-358

Owen AL, Weil DN (1998) Intergenerational earnings mobility, inequality and growth. J Monet Econ 41:71-104

Page ME, Solon G (2003) Correlations between brothers and neighboring boys in their adult earnings: the importance of being urban. J Labor Econ 21:831-855

Raaum O, Salvanes KG, Sorensen EO (2006) The neighborhood is not what it used to be. Econ J 116:200222

Sacerdote B (2007) How large are the effects from changes in family environment? A study of Korean American adoptees. Q J Econ 122:119-157

Shorrocks AF (1978) The measurement of mobility. Econometrica 46:1013-1024

Solon G (2004) A model of intergenerational mobility variation over time and place. In: Corak M (ed) Generational income mobility in North America and Europe. Cambridge University Press, Cambridge, pp 38-47

Yaari M (1965) Uncertain lifetime, life insurance, and the theory of the consumer. Rev Econ Stud 32:137150

Zilcha I (2003) Intergenerational transfers, production and income distribution. J Public Econ 87:489-513 